\title{
SCFA LEAD LAB TECHNICAL ASSISTANCE REVIEW OF THE PIT 7 COMPLEX SOURCE CONTAINMENT
}

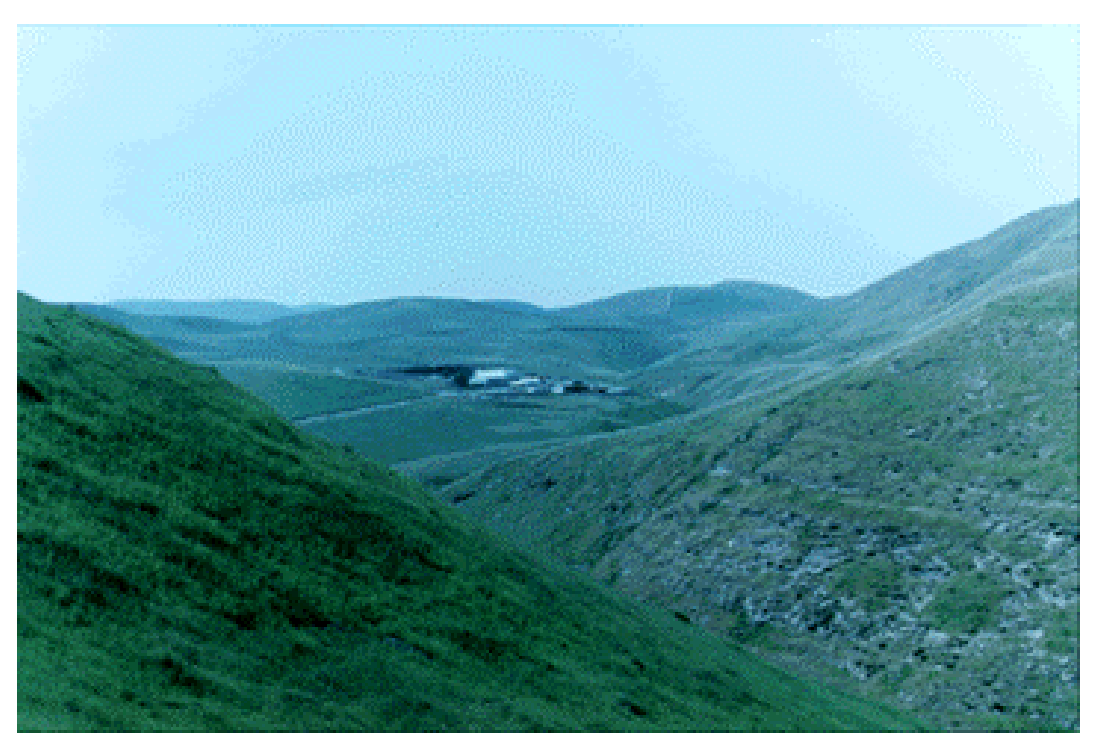

TECHNICAl ASSISTANCE REQUeST: LLNL \#1

LAWRENCE LIVERMORE NATIONAL LABORATORY JANUARY 29-30, 2001 


\section{TABLE OF CONTENTS}

I. EXECUTIVE SUMMARY ......................................................... ${ }^{2}$

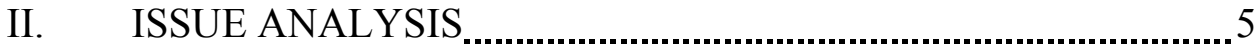

III. CHARACTERIZATION RECOMMENDATIONS ...................... 5

A. Source Characterization ...................................................... 5

B. Groundwater System Characterization ................................... 6

IV. REMEDIAL TECHNOLOGY EVALUATION ............................ 7

A. Excavation ............................................................................. 8

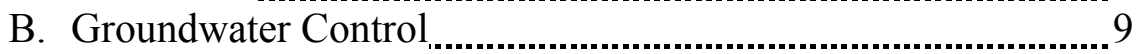

C. Pump and Treat ................................................................. 11

D. Cryogenic Freezing .......................................................... 12

E. Colloidal Silica ................................................................. 13

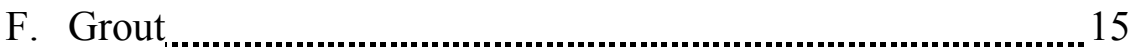

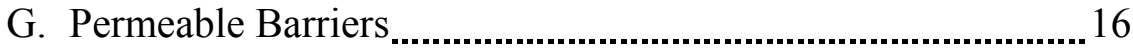

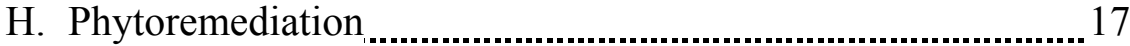

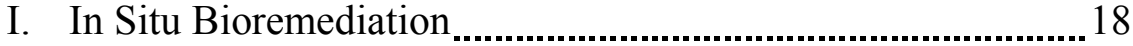

J. Monitored Natural Attenuation ........................................... 20

V. SUMMARY AND CONCLUSIONS .................................... 21

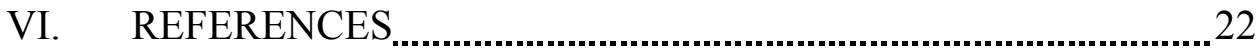

APPENDIX A REMEDIAL TECHNOLOGY MATRIX .....................23

APPENDIX B PARTICIPANT LIST ............................................ 26

APPENDIX C TECHNICAL ASSISTANCE REQUEST ....................27

APPENDIX D REMEDY SELECTION PROCESS ............................ 30

APPENDIX E PHOTOGRAPHS 


\section{SCFA LEAD LAB TECHNICAL ASSISTANCE REVIEW OF THE PIT 7 COMPLEX SOURCE CONTAINMENT Lawrence Livermore National Laboratory January 29-30, 2001}

\section{EXECUTIVE SUMMARY}

On January 29-30, 2001 a technical assistance team (TAT) met with the Pit 7 project team at Lawrence Livermore National Laboratory (LLNL) to review technologies being evaluated for remediation in the Site 300 Pit 7 Complex and the process for selecting these technologies. Specifically, the project team presented the TAT with a core need to identify technically and economically practicable technologies and methods to stabilize, contain, or control the tritium and uranium in the source areas at the Pits 3 and 5 landfill area to prevent further releases of these contaminants to groundwater and the migration of tritiated and uranium-contaminated groundwater. The approaches and needs for the systems surrounding the landfills were also presented and discussed. With encouragement from the project team, the TAT expanded its focus to include additional site characterization, a water balance model, and computational models. The TAT was comprised of leading technical and regulatory experts from around the country and was assembled by SCFA's Lead Lab in response to a technical assistance request from John Ziagos, Project Manager for the Pit 7 Area (Technical Assistance Request: LLNL \#1). A list of the TAT members is included below and contact information the TAT members and site participants is in Appendix B.

To familiarize the TAT assistance team with Pit 7 Complex issues, the project team gave a presentation outlining the site geology, contaminant hydrogeology, land-use issues, stakeholder concerns, regulatory requirements, groundwater flow and transport modeling efforts, pit source characterization efforts, and remedial options. Time for clarification and questions between the TAT and the site team was integrated into the presentation schedule. On the morning of the second day, the TAT reconvened with the site team and John Evans of the TAT presented information about a helium soil gas survey method that could potentially be used to locate and characterize tritium hot spots in Pits 3 and 5. Following the presentation, the TAT gathered independently to identify issues that are critical to remedy selection and to list questions or information gaps that the site is trying to resolve. Critical issues and questions identified by the team included:

Critical Issues:

1. Groundwater flow and water table variation

2. Complex geology/hydrogeology results in considerable uncertainty in predicting mass transport and contaminant migration. For example, weathered bedrock on hillside may cause changing water table and anticlines/synclines/faults complicate groundwater flow understanding

3. Regulations: the California non-degradation policy for groundwater 
4. Contaminants of concern (COCs): Pits $5 \& 7$ - U, Pits $3 \& 5$-tritium; volatile organic compounds (VOCs) are present in Pit 5, some metals, perchlorate and $\mathrm{NO}_{3}$ is also present - these are not COCs

(Critical Issues Continued)

5. Safety concerns: potential high explosives in pits, as well as pressurized gas cylinders; non intrusive/minimally intrusive technology preferred

6. Public perception is that monitored natural attenuation (MNA) should not currently be supported without source removal. The definition of source with respect to removal is key to feasibility of this option.

Key Questions/Information Gaps

1. How can tritium hotspots be located?

2. How many hotspots can go undetected (what are radioactivity constraints for hotspots)?

3. What is the impact of the Elk Ravine fault on groundwater flow and plume migration?

4. Preliminary information indicates that the north portion of fault is an aquitard, but what does it take to demonstrate this?

5. What impact does the south portion of the Elk Ravine fault have on groundwater flow?

6. How can uranium hot spots/source areas in Pits 5 and 7 be identified and characterized?

7. How can the contamination characterization and remediation distinguish between natural and manmade isotopes?

8. What is remaining impact of tritium in soil moisture?

9. What additional (if any) characterization needs to be done?

10. What level of heterogeneity needs to be further characterized to allow contamination control, remediation and continued monitoring?

11. Are beryllium and technetium-99 COCs?

12. Definition of contamination source with respect to source removal? Are high concentration zones associated and outside of the pits included in the definition of source for control and containment activities?

Following identification of critical issues and key questions, the TAT discussed characterization efforts underway at the site and determined areas where additional characterization data is needed. Based on this discussion, the TAT generated several characterization recommendations that are outlined in Section III of this report. The TAT created a remedial technology matrix aid in it's evaluation of the potential viability of various remedial technologies for use in Pits 3 and 5 based on critical technical, financial, and regulatory/public acceptance criteria. The full matrix is included in Appendix A. Ultimately the team came to a consensus on the following overarching recommendations.

- The site should focus immediate efforts on additional characterization and modeling before choosing a final remedy.

- Interim actions involving hydrologic control and MNA should be pursued to prevent or limit further release of tritium and uranium to groundwater. 
- A final containment, in situ treatment, or stabilization remedy should not be pursued until additional information is available regarding the contents of the Pits, hydrogeology of the weathered rock on the surrounding western hillside, contaminant point source distribution, and hydrologic impacts of the Elk Ravine Fault. The 3-D model of contaminant flow and transport at the site should be completed and exercised in sensitivity studies to assist in making a remedial action decision. 


\section{ISSUE ANALYSIS}

The key issues can be summarized into three main areas: complex geohydrology, the known and potential contaminants, and the requirements and expectations for cleanup and controls of contaminants. The geologic environment of the disposal pits creates a complex and dynamic hydrologic environment for contaminant migration. Groundwater flow in the near surface is episodic and creates local changes in water flow into the pits with oscillating water levels. Around the pits, the presence of weathered bedrock on hillsides, coupled with location in topographic valley lows, appears to focus water flow towards and through the pits. Away from the pits, mass transport of water and contaminant migration is complicated by anticlines, synclines and faults in the subsurface geologic units. All potable waters in the saturated zone below the area of the pits and contaminated zones are regulated as drinking water sources, per California standards. Primary COCs include uranium in Pits 5 and 7 and tritium in Pits 3 and 5. In addition, Pit 5 is known to contain volatile organic carbon contaminants, some metals, perchlorate and nitrate, although none of these are listed as COCs. Beryllium and other radionuclides (e.g., technetium-99) may also be present in minor concentrations. Within the pits, high explosives and residues and pressurized gas cylinders are a safety concern for characterization and remedial action activities. This concern drives preferences for non-intrusive or minimally intrusive technologies. For overall remedial actions, MNA appears to be an acceptable remedial action for tritium when combined with source removal. Tritium source removal will be driven by stakeholder concerns and regulatory requirements. This source removal effort could involve a volume greater than the pits due to the high tritium concentration zone directly associated with the pits and containment, stabilization and/or removal of other contaminants such as uranium.

\section{CHARACTERIZATION RECOMMENDATIONS}

The team commends LLNL on their characterization efforts to date, especially considering budget limitations and the constraints to intrusive sampling in the pits. The TATs characterization recommendations are divided into two categories: (1) those related to characterization of the source in the pits, and (2) those related to characterization of the groundwater system.

\section{A. Source Characterization}

- It would be worthwhile to make another attempt to retrieve historical information on materials that were used in tests and resulted in pit waste. This effort may require access to classified information, and it should involve interviews with personnel directly involved in the tests. In addition to questioning interviewees about disposal practices, the TAT recommends research into:

- The design and purposes of the tests

- Time periods associated with various types of tests and/or testing practices (which may help narrow down locations of different types of sources in pits)

- The methods by which the pits were filled and covered

- Components that were included in tests

- Beryllium materials - were they or their remnants disposed of in pits? 
- Beryllium in the environment is receiving increased attention within the DOE complex. Future source characterization efforts should include beryllium measurements in soil, as beryllium levels may affect remediation costs and possibly limit the choice of remediation alternatives. The scope and extent of Be characterization efforts should be based on the historical information.

- Future source characterization efforts should include a search for elemental signatures of high explosives (HE) in the pits as the presence of high explosives in the pits could influence costs and choices of remediation alternatives. The TAT will provide additional information on pertinent signatures and experience within the DOE complex for HEs at the project team's request.

- Soil gas surveys, and in particular helium-3 measurements, may help in determining the distribution of tritium in the pits, including possibly pinpointing potential discrete sources of tritium. John Evans of the team made a short presentation on how this method was applied at Hanford (Olsen et al., 2000, Olsen et al., 2001).

- Non-intrusive geophysical characterization methods such as ground-penetrating radar (GPR) and electromagnetic inductance (EMI) might yield valuable information on the location of large metallic components in the pits that might be discrete sources or that should be avoided during more intrusive operations (e.g., soil gas sampling). These methods, in concert with ${ }^{3} \mathrm{He}$ soil gas measurements, could be quite effective in assessing distribution of the tritium source.

\section{B. Groundwater System Characterization}

- Measuring uranium isotopic ratios in groundwater samples, including determining whether or not uranium-236 is present, would reduce uncertainty in the spatial extent of the DOE produced uranium plume by helping to distinguish DOE introduced uranium from natural background uranium.

- Technetium-99 can be used as an indicator that groundwater transport pathway for uranium. Technetium-99 is typically associated with most forms of depleted uranium and will transport relatively conservatively through the groundwater system acting as a harbinger for uranium migrating from the pits, which is significantly more retarded with respect to vadose zone leaching and groundwater transport.

- Geophysical characterization of the hillside to the west of the pits would help determine the contouring of the colluvium-bedrock contact, which could influence the planning and design of water control measures. GPR and seismic methods may be most appropriate, although other methods including electrical resistivity should also be considered. LLNL is known to have outstanding capabilities for geophysical characterization that could be applied to this problem. We suggest contacting Abe Ramirez at LLNL (925-422-6909) for further information.

- The 3-D modeling effort for the groundwater system should be aggressively pursued as it will support (1) sensitivity studies that can help prioritize hydrologic characterization efforts, (2) 
decision making on remediation alternatives, and (3) quantification and communication of uncertainties.

- The water balance study is an important aspect of the groundwater system characterization effort. This study should include estimates of uncertainties and their propagation in the water balance. The TAT suggests that consideration be given to conducting tracer tests on the hillside to the west of the pits to help address uncertainties in the distribution of flow between the colluvium and bedrock and the flow heterogeneity within these subsystems. These tests would be a relatively inexpensive add-on, to the planned water balance study. Fluorinated benzoates (FBAs) could be used as tracers in tomography experiments involving several different source and measurement locations. The FBAs should transport conservatively, and as many as 15 different ones can be readily distinguished and quantified by high performance liquid chromatography. The TAT can provide additional information on the use of FBAs as groundwater tracers (Farnham et al., 2000).

- The water balance study should be integrated with an upgradient water control remedial action (e.g., water diversion). For instance, any trenches installed for water control could be instrumented for distributed water collection/flow measurement. Documentation of the initial state of water flow and balance in the system will be valuable for demonstrating the success of water control remedial actions and potential degradation.

- Hydrologic characterization of the Elk Ravine fault is another important aspect of the groundwater system characterization effort. The TAT recommends a phased strategy in which the first priority is to obtain and analyze groundwater samples from both sides of the fault for major cations ( $\mathrm{Na}, \mathrm{K}, \mathrm{Mg}$, and $\mathrm{Ca}$ ) and anions $\left(\mathrm{F}, \mathrm{Cl}\right.$, and $\left.\mathrm{SO}_{4}\right)$, trace elements $(\mathrm{B}, \mathrm{Mn}, \mathrm{Sr}, \mathrm{Ba}$, etc.). Much of that data could exist already and simply requires additional examination and interpretation. Advanced characterization methods employing isotopic ratios (e.g., Sr-86/87, U234/235/236/238, D-2/H, O-18/O-16) can also be used to determine if the waters have distinct geochemical signatures. If the water chemistries were distinctly different, this would support interpretations that the fault is a no-flow boundary in the region of the data collected, and depending on how convincing the data are, further characterization may not be necessary. If the water chemistries are not significantly different, more expensive characterization efforts, such as aquifer testing might be warranted. The strategy should be continually re-evaluated for its adequacy and necessity as new information becomes available.

\section{REMEDIAL TECHNOLOGY EVALUATION}

The TAT evaluated several remedial options for controlling tritium and uranium source areas at the Pits 3 and 5 landfill area. These remedial alternatives parse into the following main categories based on the technology's function including: removal, hydraulic control, ex situ treatment, in situ treatment, and MNA.

Excavation, the baseline technology for remediation, is the only removal technology considered by the TAT. Removal technologies physically remove the contamination. Hydraulic control includes diversion of water by physically directing water flow up-gradient of the contaminated area, or by containing the plume by pumping the contaminated water downgradient of the contaminated area and reinjecting it back into the plume, or otherwise disposing 
of it. Containment barriers can either be impermeable or permeable. Impermeable containment strategies evaluated by the TAT included colloidal silica injection, grout injection, and cryogenic barriers. These impermeable containment barriers are designed to physically isolate the contaminants to prevent further migration, to divert the flow of water around the waste, and to limit the intrusion of water into the area of concern. Grouting and silica can also be used to stabilize the source material by immobilizing it to decrease leachability. The sole permeable containment strategy discussed during the meeting was permeable reactive barriers. As opposed to impermeable containment strategies, permeable barriers allow groundwater to flow through reactive media that treats, immobilizes, or reduces the toxicity of the contaminants. Several treatment options were evaluated for applicability to the Pits 3 and 5 areas including both ex situ (pump and treat), and in situ (bioremediation and phytoremediation). Finally, monitored natural attenuation was also considered.

In order to effectively compare and evaluate potential technologies, the TAT identified core decision-making criteria including: effectiveness, permitting risk, implementability, health and safety, public acceptance, cost, long-term liability, and technical maturity. The TAT then discussed these criteria for each technology, thus developing a large matrix. Following analysis, the group reached consensus that none of the remediation technologies evaluated were obvious choices for the Pits 3 and 5 landfill area. Furthermore, successful deployment of many of these technologies would hinge upon site-specific information regarding hydrology, geology, and contaminant transport that are, at this time, incomplete or uncertain. Thus, the TAT recommends that LLNL conduct further characterization of the site before selection of a final remedy. Each technology summary is provided below to help LLNL identify what additional characterization and monitoring techniques are necessary to enable final remedy selection. A complete description of a full remedy selection process is found in Appendix D. Due to time constraints, the TAT used an abbreviated version of this method. High, medium, or low rankings were assigned to Permitting Risk, Health and Safety Risk, and Long-Term Liability categories. In these categories, a high ranking indicates either a large degree of uncertainty or one or more significant problems that might limit use of this technology. A medium ranking signifies moderate, but not critical limitations, while a low ranking indicates that the technology is generally acceptable within the category. Public acceptability was also ranked from high to low; however, in this case, a high score signifies that the technology was likely acceptable to the public; a medium ranking indicates that one or more aspects of the technology would likely cause public concern; and a low score means that the public would likely show great reluctance to support this, or similar technologies, in the near future.

\section{A. Excavation}

The TAT believes that excavation should be considered the baseline technology for remediation of Pits 3 and 5. Excavation would involve content removal within the boundary of the pits. This could be achieved using a remote handling rig, or through use of a conventional backhoe.

Following excavation, waste would be treated if necessary, and then disposed of either on site or off site. Disposal of the excavated material would require transporting the waste to an approved disposal facility.

\section{Effectiveness:}

Excavation is the baseline technology for handling both the uranium and tritium; therefore, unless there is a fatal flaw, this technology is considered the most effective solution. Excavation 
is the most effective for treating the uranium because the source term would have been removed. For tritium, the effectiveness is considered moderate to low because it is likely that much of the tritium has already leached into the vadose zone, which is not being considered for excavation as part of the source. 


\section{Permitting Risk:}

The permitting risk associated with excavation is low, and should make MNA acceptable for the rest of the plume because the source has been removed. However, obtaining a permit for an onsite disposal facility may present an issue if waste is permanently kept on site.

\section{Implementability:}

The implementability of excavation is good as it is a tried and proven process; however, the site does have access constraints that will require significant planning and scheduling. Depending on characterization of the pit contents, treatment of the excavated soil could be required if contaminants such as HE or Resource Conservation and Recovery Act (RCRA) wastes are found. Treatment is more likely to be required if the wastes are expected to be transported offsite for disposal. Also, because excavation is intrusive, the presence of HE, compressed gas cylinders, and other, as yet unknown contaminants may require remote excavation techniques and special handling.

\section{Health and Safety Risk:}

Health and safety risk was considered high because of the still unknown contents that might be buried such as HE, compressed gas cylinders, and beryllium.

Cost: This is the baseline. Cost may be comparatively high.

\section{Public Acceptability:}

Public acceptability of excavation followed by off-site disposal was considered high because this removes the source of future contamination. Transportation of the waste to Envirocare or another on or offsite disposal facility could generate public concern, as disposal of pit contents would require approximately 1000 truckloads or 250 rail car shipments. Public acceptability of excavation followed by on site disposal was considered moderate because this requires source removal, but avoids safety issues associated with transportation of the waste. The perceived benefits of source removal were considered to outweigh the perception of the hazards of transportation.

\section{Long-Term Liability:}

Excavation will minimize liability if the source term is removed and the ultimate disposal is offsite. Long-term liability is expected to be decreased for on-site disposal through development of a robust disposal site. However, regardless of on or off-site disposal, DOE will retain some responsibility for the waste.

\section{Technical Maturity:}

Excavation and disposal are widely practiced and are considered mature technologies.

\section{B. Groundwater Control}

One of the more promising approaches discussed involves the use of active or passive control of water entering the system underneath the pits. By intercepting the water that reaches the pits from either the colluvial or bedrock flow systems, it is intended that during high rainfall events, large rises in the water table could be reduced or eliminated, thus mitigating further release of 
tritium and uranium from the source region. Colluvial flow would be intercepted by installation of a gravel-lined trench upslope from the site in the northern end of the Pit 7 Complex where the depth of the colluvium is likely not too deep. A nonpermeable lining on the downstream side of this trench should perhaps be considered to prevent inflow of tritium-contaminated water from the source area in the event of a flow reversal during wet periods. If possible, water would be gravity fed from the trench to a down-gradient location for surface disposal. The collection, transport, and re-introduction of this groundwater in a subsurface gravel filled trench or similar manner could possibly be used to avoid issues with creating wetlands by surface release.

Water entering the system along the bedrock is more problematic since the system in question is deeper and positive control would be needed through installation of suitably placed wells. The problem is further exacerbated by the relatively low permeability and correspondingly limited well productivity expected, which would likely require installation of a large number of closely spaced vertical wells or more-costly horizontal wells. Since draw down of the wells would inevitably cause a significant cone of depression, some intrusion of tritiumcontaining water is likely, with attendant difficulties associated with treating tritiated water. If this strategy is adopted, monitoring wells between the pumping wells and the source area should be considered to provide early warning of tritium migration toward the pumping wells. The water balance study, in conjunction with hydrologic characterization of the colluvium and the $\mathrm{Tnbs}_{0}$ (bedrock layer) will help determine how many pumping wells are required. Alternatively, these studies may indicate that flow through the bedrock will be low enough even during wet periods that it is not necessary to pump the bedrock to prevent inundation of the pits, provided that flow through the colluvium is controlled. LLNL is currently placing a large emphasis on this strategy as a means of interim stabilization, which will allow for in situ decay of tritium in the source region. The TAT agrees that further characterization and design efforts associated with groundwater control are worthwhile and should receive a high priority. The following assessments were made with regard to this technology option:

\section{Effectiveness:}

Effectiveness of the proposed control measures is difficult to fully assess without more detailed hydrologic characterization and modeling results. Diversion of water from up-slope is likely to have some effect on the reduction of leaching of the contaminants of concern and may help with the MNA approach. Unfortunately, since the strategy is intended to prevent incursion of water during extreme climatic conditions that occur very infrequently at most (i.e., decades apart), it will be almost impossible to test. Ultimately, the effectiveness will be tested through modeling, which by itself could prove challenging. However, installation of a trench would provide a great deal of information on the hydrologic properties of the colluvium system, which would help reduce uncertainty in the modeling efforts. The trench would also assist in the water balance studies.

\section{Permitting Risk:}

While this approach is at least worthwhile as an interim measure, it might be difficult to use this as the only remedy in support of MNA. Reinjection of tritium bearing water could present a serious problem in the future. 


\section{Implementability:}

Installation of a suitably placed trench could prove challenging because of topographic constraints. In the southern end of the Pit 7 Complex, the depth of colluvium may make trenching very expensive. Otherwise, the approach seems feasible.

\section{Health and Safety Risk:}

Risk factors should be relatively low since there is no treatment involved.

\section{Cost:}

Cost is estimated to be in the mid range for the options considered at $\$ 10-30 \mathrm{M}$. However, if the strategy is continued for more than 75 years, total life-cycle costs could be much higher.

\section{Public Acceptance:}

It is unlikely that this approach would receive good public acceptance if proposed as a standalone strategy. If used in conjunction with other remedies it should be well received.

\section{Long-Term Liability:}

Assuming this approach is effectively maintained for the foreseeable future, this approach should allow the tritium source to decay to insignificance. This method will also prevent the uranium source from being leached; however, since the uranium source is not removed by this method, it is a holding action at best and the long-term liability would remain significant.

\section{Technical Maturity:}

Taken individually, the technologies involved are routine (i.e., trenching, well drilling, groundwater modeling); however, the system proposed is ad hoc in nature and must be adapted to a moderately complex, and at this time, incompletely characterized geologic system. For that reason the technology cannot be legitimately classified as mature.

\section{Pump and Treat}

Pump and treat is widely used for remediation of groundwater plumes. However its effectiveness is highly variable and often controversial. This technology involves installation of wells that extract contaminated groundwater and then treat the water appropriately to remove the COCs. At best, any type of pump and treat approach would address only uranium, as no practical or cost-effective technology is available for ex situ separation and treatment of tritiated water. Removal of uranium from impacted groundwater is feasible; however, it is not a useful method for source treatment for uranium stranded in the pit or vadose zone. Because the productivity of existing wells in the $\mathrm{Tnbs}_{0}$ (bedrock) is known to be very low, close spacing of wells would be needed (i.e., 2-5 feet) to achieve any kind of useful result. Such close spacing would be very expensive. Because of the relative thinness of the Tnbs 0 , horizontal or highlyangled wells may be preferable to vertical wells. If characterization efforts reveal that vertical fractures conduct a significant amount of the water through the bedrock, horizontal wells would be even more attractive. Because the DOE contribution to uranium levels in the groundwater plume are relatively low already in an area with an inherently high natural background, it would be difficult to justify such a large expense for little perceivable benefit. The TAT decided that further consideration of pump and treat was undesirable. 


\section{Effectiveness:}

Pump and treat would not be effective for tritium since no practicable technologies for separation or treatment of tritiated water currently exist. Overall effectiveness of pump and treat for uranium would also be limited since much of the uranium inventory is stranded in the vadose zone where it cannot be captured using a pump and treat system. Furthermore, because leaching and transport of the uranium from the vadose zone is relatively retarded, a pump and treat system may be operational for several years before significantly impacting uranium concentrations.

\section{Permitting Risk:}

Pump and treat is widely accepted by regulators, thus permitting risk is low.

\section{Implementability:}

This technology is easy to implement; however, because it does not address tritium, the ultimate fate of extracted tritiated water is unclear and a disposal site may be needed.

\section{Health and Safety Risk:}

Disposal of tritium bearing water after uranium treatment also poses a serious problem.

\section{Cost:}

Cost for implementation of a pump and treat system is likely high, particularly because close well spacing would be needed to effectively remediate the plume.

\section{Public Acceptance:}

Since pump and treat will not remove the source term, and will not effectively treat the tritiated water, public acceptance for this technology is likely to be low.

\section{Long-Term Liability:}

Liability issues could be significant because pump and treat does not remove the source term.

\section{Technical Maturity:}

Variants on this technology are widely used and are clearly mature.

\section{Cryogenic Freezing}

Cryogenic barriers are designed to physically isolate contamination by forming a frozen containment wall. The frozen zone is created through circulation of heat exchange solution through wells placed in the subsurface. As the subsurface is cooled, soil moisture freezes, and a continuous barrier is formed both preventing migration of the contaminants downward and horizontally, and preventing groundwater entry into pits. Angled or horizontal heat exchange wells can be established using directional boring.

\section{Effectiveness:}

The effectiveness of this technology is expected to be high for the lifetime of the project for contaminants contained within the frozen barrier, isolating both tritium and uranium from exposure to groundwater. However, it is expected that the lifetime of this type of solution is less 
than the 75 years required for the tritium to decay to safe levels. Freezing also does not provide a permanent solution for uranium, and it does nothing to mitigate the transport of contaminants that are initially outside the barrier. Use of this technology would be most valuable as an interim approach, coupled with development of long-term containment and/or stabilization technologies.

\section{Permitting Risk:}

Difficulty of permitting is likely moderate, as this technology has not yet been applied to contain tritium.

\section{Implementability:}

This technology has been deployed for control of water, but has not been deployed to contain tritium.

\section{Health and Safety Risk:}

Health and safety risks for installation of the barrier are considered moderate, although maintenance will not involve substantial worker risk. Health and safety risks can be minimized through the use of concentrated calcium chloride brine as a heat exchange solution rather than liquid nitrogen or carbon dioxide.

\section{Cost:}

Maintenance costs for cryogenic barriers are low; however, the initial cost of barrier installation using horizontally bored holes is expected to approach the $\$ 50 \mathrm{M}$ range. Installation costs may be lower with the use of angular drilling from the sides. A significant factor affecting the upfront barrier emplacement cost is the number of wells that will be required to adequately freeze the area. The use of calcium chloride solutions to replace the liquid nitrogen or liquid $\mathrm{CO}_{2}$ lowers costs as well as reducing health and safety risks associated with volumetric changes from cryogenic liquids to gases.

\section{Public Acceptance:}

Public acceptance of this technology is expected to fall within the medium range. The technology concept is easily understood by the public and is easily reversible. However, it is a relatively new technology and is neither a long-term solution, nor a permanent fix.

\section{Long-Term Liability:}

This solution is considered an interim solution only, and must be combined with other measures to control long-term liability.

\section{Technical Maturity:}

This technology could be deployed while developing solutions that are more permanent. The technology has been deployed to contain uranium at ORNL and to control water flow at a wide variety of industrial and infrastructure sites.

\section{E. Colloidal Silica}

Colloidal silica injected as a viscous liquid barrier can be used to either form an impermeable barrier deflecting water around the waste or to encapsulate the waste preventing mobilization of 
waste contaminants. Installation of the barrier requires well emplacement for injection of the viscous silica, which then hardens over time.

\section{Effectiveness:}

Injection of colloidal silica around the perimeter of the pit does not address groundwater rising from the bedrock where it contacts the bottom of the pits allowing exposure and a route of contamination to groundwater; however, injection to encapsulate the waste would isolate contamination. There are questions about the long term-effectiveness of this technology when the area goes through continuous drought cycles followed by El Niño events that may inundate the pits. These droughts could cause drying and result in fractures. The possibility of colloidal transport of uranium sorbed on the silica also raises questions about the long-term effectiveness of this technology. Deployments to date have not reduced permeability as effectively as originally hoped. Also, injection of the colloidal silica, although potentially effective in immobilizing contaminants in the vadose zone, will tend to displace contaminated groundwater, which may result in a "slug" of contamination being added to the plume.

\section{Permitting Risk:}

The permitting risk would likely be high without additional performance data demonstrating effectiveness of this technology; however, it may be acceptable as source control if used in conjunction with MNA.

\section{Implementability:}

This is an intrusive technology that may be difficult to implement. Fracturing could occur during installation.

\section{Health and Safety Risk:}

If injection is performed around the pit, risks are low. However, injecting silica directly into the waste pits increases risk to medium or high.

\section{Cost:}

If colloidal silica is used to form a barrier, costs are expected to be in the medium range of \$30$40 \mathrm{M}$. If used to encapsulate all of the waste within the pits, the costs are expected to approach the high range of $>\$ 50 \mathrm{M}$.

\section{Public Acceptance:}

Public acceptance of this approach is considered medium. Stabilization such as grouting of waste is generally not considered a permanent solution by stakeholders.

\section{Long-Term Liability:}

This technology is considered an interim solution only and should be used in combination with a long-term remedy.

\section{Technical Maturity:}

This technology has been demonstrated and deployed at Brookhaven National Lab in sandy soils. As with most attempts to reduce the permeability of soils, actual deployment resulted in less permeability reduction than was predicted by laboratory tests by at least an order of magnitude. Also, the silica injection apparently resulted in displacement of contaminated water that caused 
temporary increases in contaminant concentrations in downgradient wells. This technology has also been demonstrated in clean sediments nearby, i.e., Los Baños, CA.

\section{F. Grout}

Grout can also be injected to form an impermeable barrier deflecting water around the waste or to encapsulate the waste and prevent mobilization of waste contaminants. Several innovative grout formulations are commercially available. For barriers, this would be considered the baseline technology, since it is proven and readily commercially available (Gavasakar et al., 1998).

\section{Effectiveness:}

Injection of grout around the perimeter of the pit does not address the upwelling of groundwater from the bedrock where it contacts the bottom of the pits allowing exposure and a route of contamination to groundwater. As with most attempts to reduce the permeability of soils, actual deployments result in less reduction than predicted by laboratory tests. Grout injection could give rise to significant local water chemistry changes (for instance, a high $\mathrm{pH}$ plume may develop), which may result in increased mobility of uranium downgradient of the barrier.

\section{Permitting Risk:}

Permitting risk is moderate for grouting technologies. Although it is widely used, this technology is invasive and does not remove the source term.

\section{Implementability:}

Installation beneath the Pits could be achieved through horizontal boring or use of a horizontal excavator developed through Industry Programs and demonstrated at Oak Ridge (www.netl.doe.gov/publications/proceedings/00/ind\%5Fpart00/em4-5.pdf). Injection of grout is likely to be more difficult than colloidal silica in most scenarios. The higher viscocity of the grout makes injection more difficult, especially in low permeability sediments and fractured rock (Moridis et al., 1999).

\section{Health and Safety Risk:}

Health and safety risks are expected to follow the same pattern. If injection is performed around the pit, these risks are low. However, injection in the waste in the pits, increases the risk to medium or high.

\section{Cost:}

Costs are expected to be in the medium range of $\$ 30-40 \mathrm{M}$ if used to form a barrier. If used to encapsulate all of the waste within the pits the costs are expected to approach the high range of $>\$ 50 \mathrm{M}$. The cost of grout is likely less than colloidal silica.

\section{Public Acceptance:}

Public acceptance of this approach is considered medium. Stabilization or grouting of wastes is not considered a permanent solution by most of the public. 


\section{Long-Term Liability:}

Grout should provide longer-term protection than colloidal silica when exposed to recurring drought/inundation cycles, but long-term viability is not well known.

\section{Technical Maturity:}

This technology is considered mature and has been used in many applications.

\section{G. Permeable Barriers}

Permeable reactive barriers (PRB) can be employed to reduce the toxicity, reduce the mobility or destroy specific contaminants of concern through interaction with a reactive media placed in the path of the contaminant flow. This flow may be in either the groundwater or the vadose zone. In many cases, the barrier is combined with a hydraulic control method that channels flow of contaminants to the area of treatment. These systems, e.g., funnel and gate, can be constructed through the use of technologies such as Envirowall. Sheet pilings can be used to direct flow toward the barrier. Uranium, one of the primary COCs in Pit 7 Complex, is immobilized either by reduction or sorption/precipitation. The most common reactive media available for uranium treatment are zero valent iron and apatite (a calcium phosphate mineral which may include some cationic and anionic substitutions). Similar to the PRB solution, $\mathrm{H}_{2} \mathrm{~S}$ can be injected into the vadose zone to form a reactive zone of ferrous iron in which the uranium is reduced and rendered immobile by strong sorption. However, because uranium is eventually subject to reoxidation and thus remobilization, the long-term effectiveness of redox-based controls is questionable. A barrier employing apatite may be more effective in the long term since it involves formation of an irreversible precipitate which is less likely to be released over time. In addition to considering mineral apatite, alternative materials, such as fish bones (Apatite II $^{\circledR}$, available from UFA Ventures, Inc.), which are high in amorphous phosphate and contain apatite crystals for enhanced nucleation of phosphate precipitates, might be considered for low-cost, highly-permeable barrier materials. Apatite II ${ }^{\circledR}$ performed well in treatability studies at Los Alamos (Conca et al., 2000).

\section{Effectiveness:}

This technology is not effective for control of the tritium, and does not provide a permanent solution as the precipitated uranium could potentially reoxidize (in the case of a reductive barrier like zero-valent or ferrous iron) in the future. The recovery of uranium from the leachate is not expected to be significant with respect to the total amount of uranium remaining in the pit. Use of $\mathrm{H}_{2} \mathrm{~S}$ has proven effective for uranium immobilization for limited time periods. However, long-term immobilization of uranium by $\mathrm{H}_{2} \mathrm{~S}$ is still under laboratory investigation. Zero valent iron barriers are prone to permeability reduction due to corrosion product formation and biofouling. Apatite barriers should be evaluated for their effectiveness in the laboratory using site groundwater, which is relatively high in calcium and therefore may reduce the affinity of the apatite for uranium because of competition with calcium for sorption and substitution sites.

\section{Permitting Risk:}

Because the technology is widely used, probability of regulator acceptance is high. Installation of a PRB may also increase acceptance of MNA as a permanent remedial solution for tritium. 


\section{Implementability:}

The iron or apatite can either be placed in trenches or closely spaced wells to react with the uranium in the groundwater. The use of this technology is dependent upon a robust understanding of the hydraulic flow in the area. The use of a validated contaminant flow and transport model is critical.

\section{Health and Safety Risk:}

While there is very little health and safety risk during installation, the replacement of reactants may cause significant worker exposure issues to uranium, its daughter products, and other contaminants. The use of $\mathrm{H}_{2} \mathrm{~S}$ triggers many health and safety concerns, but has been used effectively in past demonstrations.

\section{Cost:}

While the installation costs are typically low, the ongoing costs of replacing reactant and disposing of spent reactant may drive these costs into the medium range.

\section{Public Acceptance:}

This technology was also ranked as medium for stakeholder acceptance. While feasible, it does not provide a permanent solution.

\section{Long-Term Liability:}

As all redox reactions are reversible, reductive barriers such as zero-valent or ferrous iron or $\mathrm{H}_{2} \mathrm{~S}$ are not considered a permanent solution for uranium, and will not affect tritium. Apatite may be more practical for reduction of long-term liability for uranium.

\section{Technical Maturity:}

This technology is considered mature and has been deployed at several locations in the DOE complex.

\section{H. Phytoremediation}

Phytoremdiation is an experimental or emerging technology that may have applicability to both the tritium and uranium. Phytoremediation involves the use of vegetation to remove the contaminants from the soil and/or groundwater and incorporate those contaminants into the plant tissue or transport it to the air via evapotranspiration. A number of studies and demonstrations have shown plants to incorporate uranium from either soil or groundwater, while other studies and demonstrations have shown that plants can evapotranspire tritium to the atmosphere from contaminated groundwater. Thus, the possibility exists for their use at the LLNL site. The public acceptability, low cost and aesthetics of using this technology are normally excellent in places where it has been used. Overall, the technology is currently considered too experimental and has a number of technical and practical deficiencies that would make it impractical for LLNL to consider at this time. The TAT provides the following specific assessments with regard to this technology option: 


\section{Effectiveness:}

Because this is an experimental technology, the relative effectiveness is unknown; however, the technology has a number of known constraints. The effective depth of root penetration into the subsurface is less than $20 \mathrm{ft}$ for trees and less than $10 \mathrm{ft}$ for most herbaceous plants. Since much of the contamination is at least $15 \mathrm{ft}$ deep, this could limit use of this technology at the site. Due to the arid nature of the site, use of this technology may also require a constant source of irrigation.

\section{Permitting Risk:}

Generally, this technology is easy to permit if enough information can be gathered to show its effectiveness. However, there are major constraints (e.g., the biomass that has accumulated the uranium must be disposed of, as often as annually, and the risk posed by exposed contaminated biomass) that could cause permitting problems that must be considered during the permitting process.

\section{Implementability:}

This technology is extremely easy to implement, as long as the biomass does not require radioactive treatment and disposal. Typically, the disposal technique involves incineration with the ash being sent to a radioactive repository. Growing the plants at the site should be easy with a minimal amount of irrigation and agricultural type maintenance.

\section{Health/Risk:}

The health risk could be low to high depending on where the contaminants were incorporated in the plant. The transpiration of the tritium to the atmosphere would constitute fugitive air emissions; however, this would be minimal and acceptable by any standards. Birds, deer, rabbits and insects could eat the plants and subsequently acquire uranium and spread it to a much wider area, though fencing and netting could control much of this dissemination. Wild fires may also result in unanticipated spread of the uranium to a wider area.

\section{Cost:}

Generally, the cost is very low since it involves minimal maintenance once the plants are established. However, disposal of contaminated biomass can substantially increase the cost if it requires incineration at a Nuclear Regulatory Commission approved incinerator and disposal of the ash in an approved radionuclide burial ground. Removal rates by the plants are typically very slow, especially as the depth increases; thus this system may have to be maintained for many years to see significant reductions in source term.

\section{Public Acceptance:}

In places where this technology has been used, it has been immensely popular with the public since it is perceived as an aesthetically pleasing, natural solution.

\section{Long-Term Liability:}

Because this is an experimental technology, long-term liability is poorly understood; however, it is expected to be high as this technology does not involve source removal.

\section{Technical Maturity:}

This technology is experimental at this time. 


\section{In Situ Bioremediation}

In situ bioremediation could be used to immobilize the uranium in place. This technology is considered experimental at this time. Two basic methods could be used to immobilize the uranium in the soil and groundwater, co-precipitation and reduction of the uranium to less soluble forms. Co-precipitation involves a process patented as Biorock (U.S. Patent 5,143,155). This involves the injection of urea, calcium chloride and bacteria into a metal/radionuclidecontaminated area. Bacteria cause the formation of calcium carbonates that co-precipitate other metals present in the waste. As long as the $\mathrm{pH}$ of the groundwater or vadose zone that has been infiltrated stays above 6 the limestone formed is stable. This process is currently experimental and has not been tried on a large scale. The other technique involves the injection of organic carbon to biostimulate indigenous bacteria to reduce the uranium present to less soluble forms. This can be done through injection of products like HRC (Hydrogen Release Compound) that basically consists of lactic acid and glycerol (www.regenesis.com/HRC/default.htm). HRC or similar compounds can be put into wells and released slowly over a number of years to provide the anaerobic conditions necessary to reduce the uranium. This technique has been widely applied for remediation at chlorinated solvents and demonstrated for chromium but is still experimental for uranium. Having to maintain an anaerobic environment indefinitely in order to keep the uranium from returning to it's more soluble state under oxidizing conditions may pose a serious challenge to the success of in situ bioremediation of uranium. Overall, this technology is too experimental and only addresses the uranium problem at the site. The TAT provides the following specific assessments with regard to this technology option:

\section{Effectiveness:}

This technology would only be effective for uranium in groundwater. It may require that anaerobic conditions be maintained indefinitely since the ability of the reduced uranium to reoxidize once the environment returns to aerobic conditions in unknown. Any injection process can potentially displace pre-existing contaminated water into more conductive flow pathways, which may result in enhanced mobilization of some percentage of contaminants in the near term. Downgradient monitoring during and after injection is therefore advisable.

\section{Permitting Risk:}

Generally, this technology is easy to permit if enough information can be gathered to show its effectiveness.

\section{Implementability:}

This technology is easy to implement, as long as stimulatory material can be injected into the source zone or into a treatment zone. Fractured rock is more difficult to inject into and requires very detailed characterization in order to be effective.

\section{Health and Safety Risk:}

The health risk is low since this technology is applied in situ and none of the injectables are hazardous or noxious. Environmental risks are minimal. 


\section{Cost:}

Generally, the cost is low since it involves only the initial installation of injection equipment and minimal periodic maintenance after that. The injectables generally cost less than electricity and operational sampling.

\section{Public Acceptance:}

Because it is perceived as a more natural solution, ISB has been immensely popular. However, the public may be more skeptical in this case since it does not involve the removal of the source.

\section{Long-Term Liability:}

This is an experimental technology and long-term liabilities are poorly understood, though they should generally be considered high since this technology does not involve source removal.

\section{Technical Maturity:}

This technology is experimental at this time.

\section{J. Monitored Natural Attenuation}

Monitored Natural Attenuation depends on the ability of the contaminant to naturally attenuate via natural biogeochemical or, in the case of tritium, radioactive physical decay mechanisms. This technology has been applied to a large number of sites with organic contaminants, which biodegrade naturally. Use of this technology is dependent upon excellent predictive contaminant flow and transport models and verification monitoring. MNA could be used for tritium due to its short half-life. An MNA strategy would have to be followed for up to 75 years. Since tritium decays with a known physical half-life (12.32 years), MNA is very practical, provided there are no surprisingly large additions of tritium associated with the source region. MNA is thus best implemented in association with some type of source removal or containment strategy. The TAT felt that while MNA is a legitimate approach for the circumstances described, it is important that some type of contingency plan be developed for dealing with potentially large excursions in tritium concentration revealed by the monitoring program. "Monitored stewardship" may be a more appropriate term than MNA to describe the applicability of this technology to uranium remediation. Monitored stewardship may be relatively easy to justify given the very low hazard potential associated with the existing uranium plume. It should be noted, however, that the same consideration for tritium also applies to uranium in that some type of contingency plan would be needed. Overall, this technology is probably one of the best solutions if it is combined with source removal; however, it may be difficult to permit without source removal. This technology requires a great deal of initial characterization and modeling to support selection as the final remedy. The TAT provides the following specific assessments with regard to this technology option:

\section{Effectiveness:}

This technology would only be effective for tritium due to the relatively short half-life; however, uranium does not reasonably attenuate due to its very long half-life. Use with uranium should be represented as monitored long-term stewardship. 


\section{Permitting Risk:}

Permitting will probably be difficult without source control or removal. Acceptability increases with other source removal or control technologies.

\section{Implementability:}

Implementation of this technology should be straightforward, as it only requires comprehensive hydrogeologic modeling and verification monitoring.

\section{Health and Safety Risk:}

The health risk is low since everything is done in situ and it involves no active intrusion of the source area.

\section{Cost:}

Generally, the cost is very low since it involves only the initial installation of monitoring wells and modeling of the site. This technology requires more initial characterization and modeling than the other technologies before it can be selected as the final remedy. Sampling can be truncated as verification of predictions proceeds, so out year costs are reduced.

\section{Public Acceptance:}

Public acceptance would probably be marginal without source removal or control. Acceptability will increase if coupled with source removal or containment.

\section{Long-Term Liability:}

Long-term liability could be high since there is no source removal.

\section{Technical Maturity:}

Not applicable, since it is not an active remediation technology. However, the enabling technologies, modeling and verification monitoring, are technically mature and in wide use.

\section{SUMMARY AND CONCLUSIONS}

LLNL made an excellent presentation of the information that they had collected to date about the problem that might lead to the selection of a remediation technology for the Pit 7 complex. The TAT believes that it received, in the short time available, a reasonable appreciation of the issues concerning the environmental characteristics of the site, public perception, and the regulatory drivers. Clearly the TAT had a very short time period to glean this information; however, the TAT is an experienced group of scientists and engineers from across the DOE complex that have dealt with similar problems at other DOE sites. The TAT believes that LLNL has done an excellent job to date in characterization of the site and suggesting possible solutions, especially given the financial constraints at Site 300 and perceived safety constraints that prevent them from sampling in the pits at this time. The TAT also understands that there are fairly strong regulatory and schedule drivers to select a remedy for the site in the near future. Since the original core task for the TAT was to provide recommendations for remediation technologies for the source contamination at the site, we have provided a matrix of technologies that might be applicable. However, given the lack of immediate risk receptors, the relatively low concentrations of contaminants, the geohydrological complexity, and the dichotomy of strategies 
that would be effective on both the tritium and uranium, we believe the best action for LLNL is to continue characterization while implementing some interim groundwater engineering controls. Interim groundwater controls, such as trenches, should also benefit the groundwater flow characterization efforts (water balance studies) if the two efforts are effectively integrated as well as most of the other potential remediation options. Thus, the first and strongest recommendations of this report are for characterization strategies and technologies. The TAT believes that this additional information on characterization will insure that the best technology for remediation of the site can be selected. Though the TAT provided a matrix of technologies that might be applicable to the site, it recommends that the characterization, modeling and interim groundwater control be pursued at this time. Collection of information on contamination containment and remediation technologies, approaches and integrated strategies should continue. Better definition of the contaminant sources, the plume, the geohydrological environment, and empirical and numerical models that accurately predict contaminant fate and transport at the site is essential to the selection of an effective remediation technology for this site.

\section{REFERENCES}

Gavaskar, A. R., N. Gupta, B. M. Sass, R. J. Janosy, and D. O’Sullivan. 1998. Permeable Barriers for Groundwater Remediation. 176p. Battelle Press, Columbus.

Conca, James L., Abdel-Fattah, Amr, Jones, Matthew W., Strietelmeier, Betty A., Ware, Doug, Espinosa, Melissa, Martinez, Bennie A., Garcia, Elmer, Kaszuba, John P., Taylor, Tammy P., and Sauer, Nancy N. 2000. Demonstration of a multiple permeable reactive barrier (multibarrier) in Mortandad Canyon: Los Alamos National Laboratory Report LA-13780-MS, 46p.

Farnham, I. M., L. C. Meigs, M. E. Dominguez, K. Lindley, J. M. Daniels, and K. J. Stetzenbach. 2000. "Evaluation of Tracers Used for the WIPP Tracer Tests", Appendix H in Interpretations of Tracer Tests Performed in the Culebra Dolomite at the Waste Isolation Pilot Plant Site, SAND97-3109, Sandia National Laboratories, Albuquerque, NM.

Moridis, G., S. Finsterle, and J. Heiser. 1999. Evaluation of alternative designs for an injectable barrier at the Brookhaven National Laboratory Site, Long Island, New York. Water Resources Research 35: 2937-2935.

Olsen, K.B., P. E. Dresel, G.W. Patton, J. C. Evans, and R. Poreda. 2000. Measurement of Tritium in Gas Phase Moisture and Helium-3 in Soil Gas at the Hanford Townsite and the $100 \mathrm{~K}$ Area. PNNL-13217.

Olsen, K. B., P. E. Dresel, J. C. Evans, G. W. Patton, J. V. Borghese, R. W. Ovink, and J. M. Faurote. 2001. Helium-3/Helium-4 Ratios in Soil Gas at the 618-11 Burial Ground. In Hanford Site Groundwater Monitoring for Fiscal Year 2000, M. J. Hartman, L. F. Morash, and W. D. Webber editors, Section 3.2.1, PNNL-13004. 


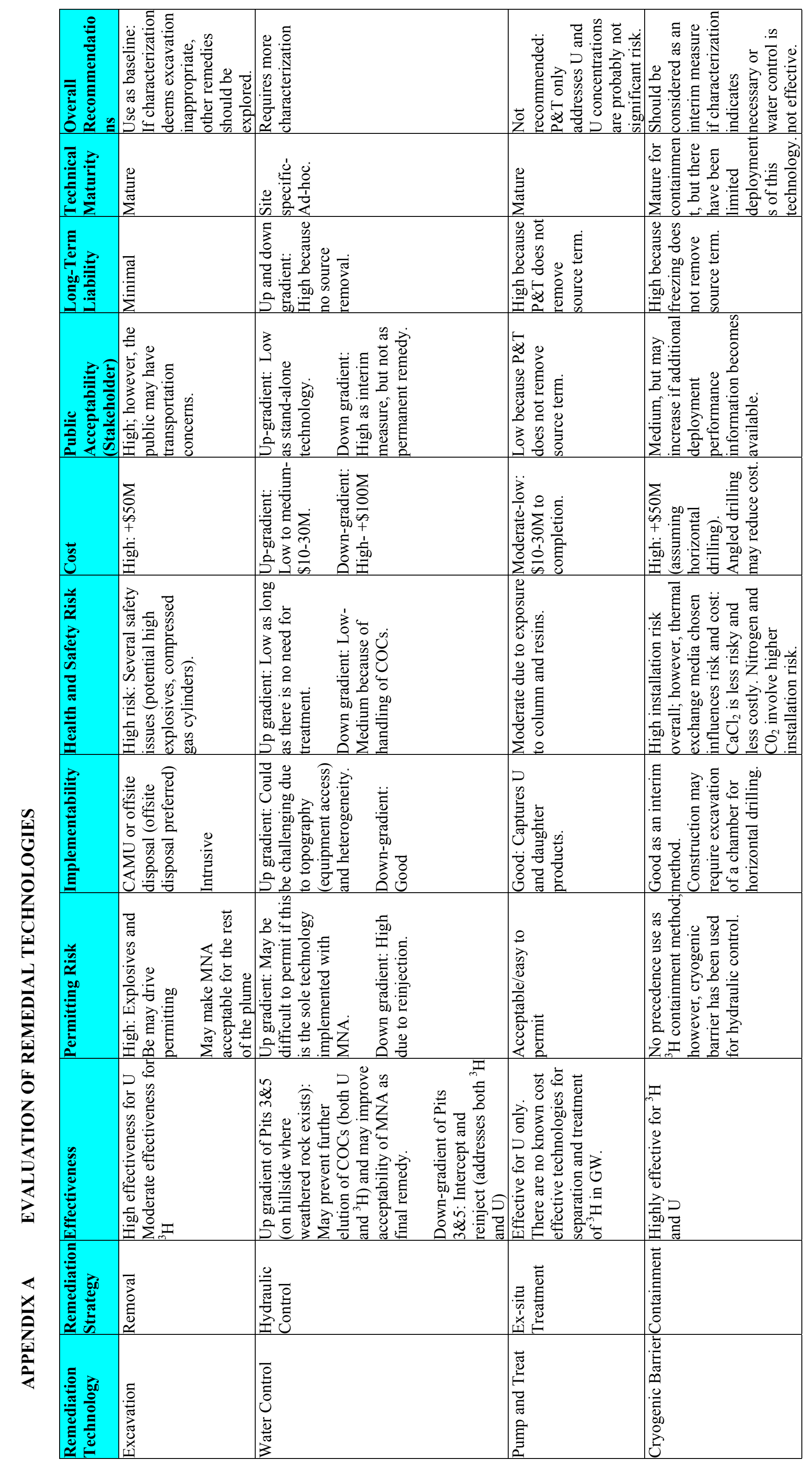




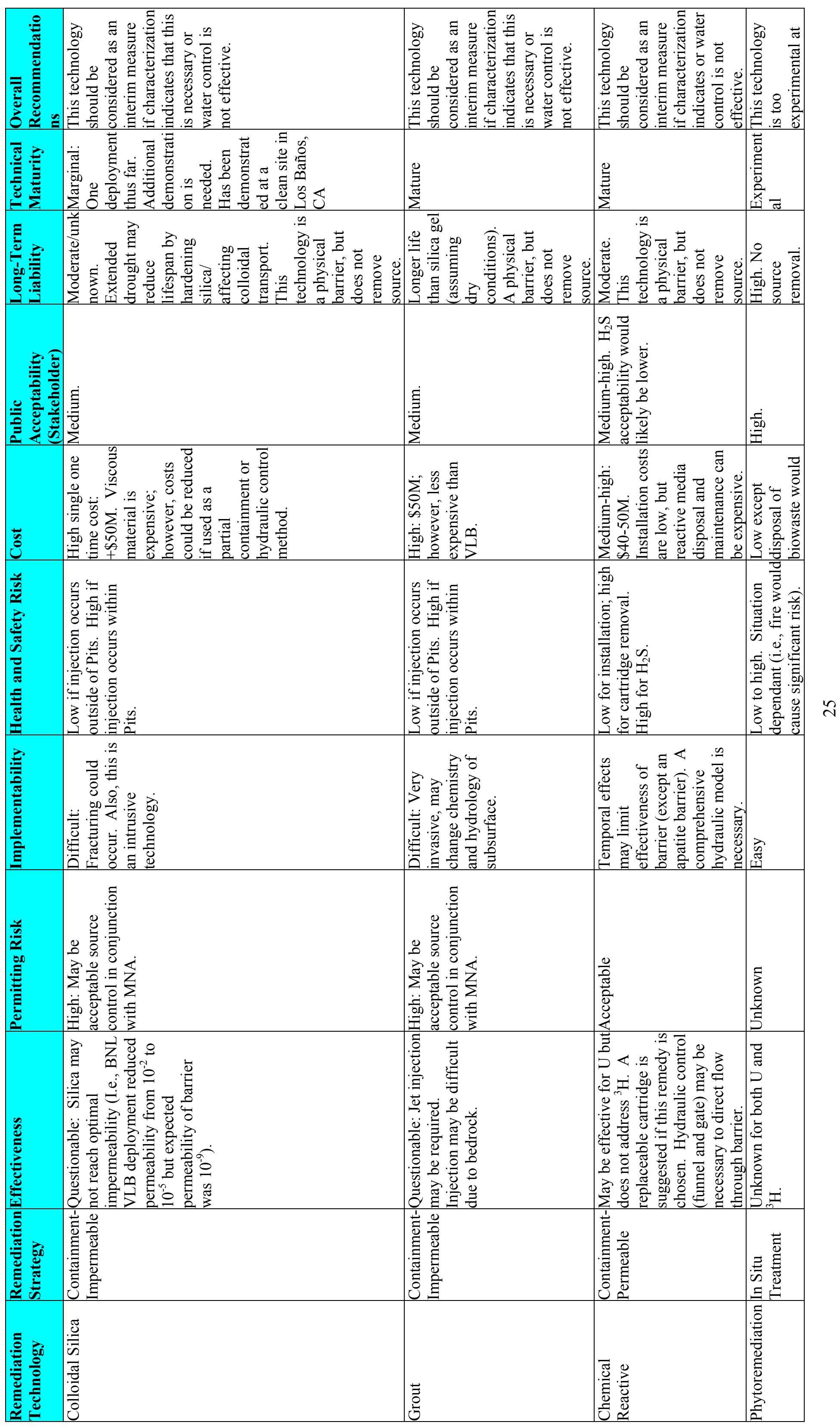




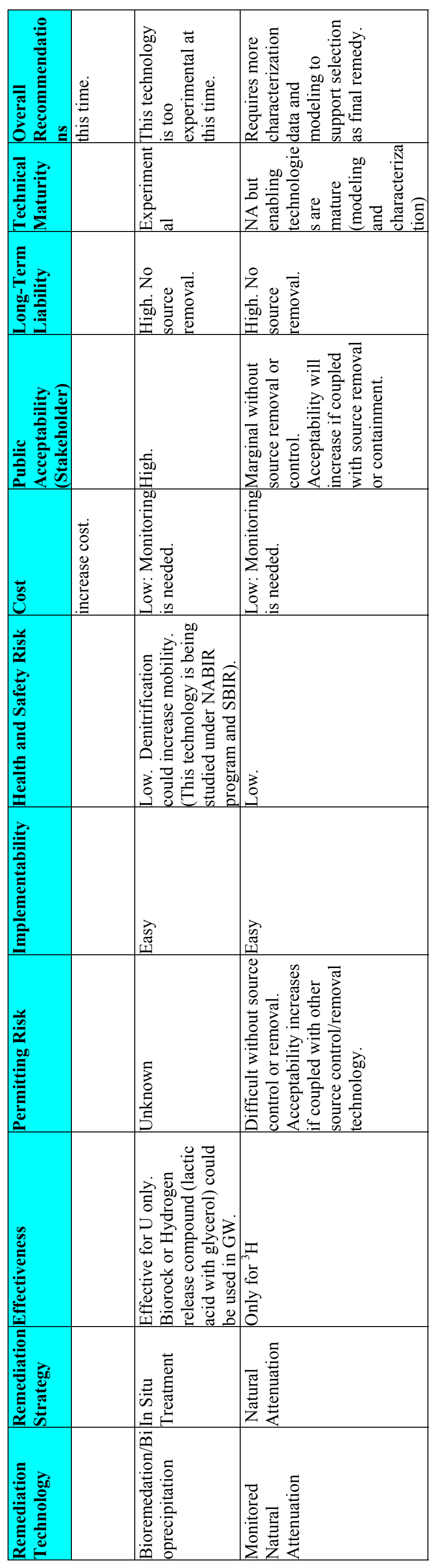


TECHNICAL ASSISTANCE TEAM

$\begin{array}{llll}\text { Dave Eaton } & \text { INEEL } & \text { 208-526-7002 } & \text { dle@inel.gov } \\ \text { David Janecky } & \text { LANL } & 505-665-0253 & \text { janecky@lanl.gov } \\ \text { Dick Woodward } & \text { LLNL } & 925-422-1885 & \text { woodward5@1lnl.gov } \\ \text { Janice Imrich } & \text { EnviroIssues } & 206-269-5041 & \text { jimrich@enviroissues.com } \\ \text { John Evans } & \text { PNNL } & 509-376-0934 & \text { john.evans@pnl.gov } \\ \text { Mike Morris } & \text { ORNL } & 865-574-0559 & \text { imi@ornl.gov } \\ \text { Paul Reimus } & \text { LANL } & 505-665-2537 & \text { preimus@lanl.gov } \\ \text { Terry Hazen } & \text { LBNL } & 510-486-6223 & \text { tchazen@lbl.gov }\end{array}$

\section{LLNL PIT 7 PROJECT TEAM}

$\begin{array}{llll}\text { Roy Kearns } & \text { DOE } & 925-422-1168 & \text { kearns2@1lnl.gov } \\ \text { Albert Lamarre } & \text { LLNL } & 925-422-0757 & \text { lamarre1@1lnl.gov } \\ \text { William Daily III } & \text { LLNL } & 925-424-4418 & \text { daily5@1ln1.gov } \\ \text { Dorothy Bishop } & \text { LLNL } & 925-422-2267 & \text { bishop2@1lnl.gov } \\ \text { Fred Hoffman } & \text { LLNL } & 925-423-6745 & \text { hoffman4@1lnl.gov } \\ \text { John Ziagos } & \text { LLNL } & 925-422-5479 & \text { ziagos1@1lnl.gov } \\ \text { Judy Steenhoven } & \text { LLNL } & 925-423-8853 & \text { steenhoven1@1lnl.gov } \\ \text { Leslie Ferry } & \text { LLNL } & 925-422-0060 & \text { ferry2@1lnl.gov } \\ \text { Michael Taffet } & \text { LLNL } & 925-422-6114 & \text { taffet1@1lnl.gov } \\ \text { Vic Madrid } & \text { LLNL } & 925-422-9930 & \text { madrid2@1lnl.gov } \\ \text { Sevin Bilir } & \text { Weiss/LLNL } & 925-424-2546 & \text { bilir1@1lnl.gov } \\ \text { Zafer Demir } & \text { Weiss/LLNL } & 925-422-8831 & \text { demir1@1lnl.gov }\end{array}$


Tracking Number:

Requesting Organization LLNL

Contact Individual: $\quad$ Dr. John Ziagos

Telephone number: $\quad 925.422 .5479 \quad$ Fax Number: 925.422 .3800

Mailing Address:

Dr. John Ziagos MS L544

Lawrence Livermore National Laboratory

7000 East Avenue

Livermore, CA 94550-9234

E-Mail Address: $\quad$ ziagos1@1lnl.gov

\section{Description of Request}

\section{BACKGROUND}

Lawrence Livermore National Laboratory (LLNL) has two operating sites, Site 300, an experimental test facility near Tracy, California, and the Livermore Site (Site 200) near Livermore, California. In accordance with the terms outlined in the Federal Facility Agreement (FFA) Site 300 is undergoing Comprehensive Environmental Response, Compensation, and Liability Act of 1980 (CERCLA) environmental restoration. The Site 3300 FFA was negotiated between the U.S. Department of Energy (DOE) the U.S. Environmental Protection Agency (EPA), California Department of Toxic Substances Control (DTSC), and California Regional Water Quality Control Board (RWQCB.) The FFA provides the framework for the conduct of the sit cleanup and preparation of necessary regulatory documents.

A Site Wide Feasibility Study (SWFS) has been prepared and approved by the regulators and is in compliance with the requirements of CERCLA as amended by the Superfund Amendments and Reauthorization Act of 1986 (SARA). The SWFS, along with the previously conducted Site-Wide Remedial Investigation (SWRI) (Wesbster-Scholten, 1994) and subsequent site characterizations at Building 850/Pits 3 and 5, Building 854, and Building 832 Canyon Operable Units (OUs), form the basis for evaluating and selecting alternative technologies for remediation of contaminants at Site 300 .

LLNL site 300 is a DOE experimental test facility operated by the University of California. The facility is located in the eastern Altamont Hills about 13 miles southeast of the main Laboratory Site in Livermore and 8.5 miles southwest of Tracy, California. Site 300 is primarily a high explosives (HE) test facility that supports the LLNL weapons program in research, development, and testing associated with weapons components. This work includes explosives processing; preparation of new explosives, and pressing, machining, and assembly of explosives components. Site 300 activities also include 
hydrodynamic testing for verifying computer simulation results, obtaining equation-ofstate data for weapons materials, evaluating material behavior at assembly joints and welds, evaluating the quality and uniformity of implosion and evaluating the performance of post-nuclear test design modifications (LLNL, 1991). Some experiments performed at Site 300 do not involve high explosives. These experiments may require more space or isolation or may have other requirements that cannot be met at the Livermore Site (U.S. DOE 1982). Access to Site 300 is restricted. Prior to August 1990, investigations of potential chemical contamination at Site 300 were conducted under the oversight of the California RWQCB-Central Valley Region. In August 1990, Site 300 was placed on the National Priorities List (NPL). Since then, all investigations, including the preparation of the SWRI report, have been conducted in accordance with CERCLA under the oversight of the three supervising regulatory agencies: EPA, RWQCB, and DTSC.

\section{INTRODUCTION TO THE PROBLEM}

Site 300 is located in the southeastern Altamont Hills of the Diablo Range, about 30 miles east of San Francisco Bay. The site covers 11 square miles (sq mi), most of which is in San Joaquin County. The western one-sixth of the site is located in Alameda County. The topography of Site 300 consists of a series of steep hills and canyons generally oriented northwest to southeast. Elevation ranges form about 500 feet $(\mathrm{ft})$ in the southeast corner to about 1,750 ft in the northwestern area. Grassland cover grown seasonally. The climate of Site 300 is semiarid and windy. The average annual rainfall for the 32-year period from 1965 through 1997 was 10.44 inches (in). During the same 38-year period the annual (July through June) total rainfall ranged form 3.82 to 23.64 inches. The most rain for one day (midnight through midnight) in the last 8 years (1992 through 1999) was 1.64 inches on 3 February 1998. The wind is predominantly from the west-southwest; the temperature extremes in 1997 ranged from 99 degrees Fahrenheit $\left({ }^{\circ} \mathrm{F}\right)$ in July to $27^{\circ} \mathrm{F}$ in January. The estimated potential evapotranspiration (defined by the U.S. Department of Agriculture as the amount of moisture a plant could use if it had all the moisture needed) at Site 300 is about 30.6 in (USDA, 1966). Site 300 has been divided into eight OUs based on the nature and extent of contamination originating at release sites identified in the SWRI. All of the OUs except one will be concerned in the current FFA/CERCLA site wide process. The remaining OU of interest for this discussion has been divided into two parts: 1) B850 and 2) Pits $3 \& 5$. B850 will be covered in the site wide FFA/CERCLA process, however the Pits $3 \& 5$ portion of the original OU is problematic and requires Lead Laboratory technical assistance. This portion of OU 5 has been renamed the Pit 7 Complex for all further discussions.

The Pit 7 Complex consists of a group of four landfills, Pits 3, 4, 5, \& 7, which were used in the past to dispose firing table debris and gravel. LLNL constructed the pits by excavating topsoil and alluvial material to an average depth of 10 to $12 \mathrm{ft}$ (Taffet et al., 1989). LLNL used these landfills to dispose of firing table debris and gravel between 1958 and 1988. The majority of the waste material in the pits came from the firing tables at Buildings 850 and 851, and included wood; plastic; material and debris from tent structures; pea gravel; exploded test assemblies; remnants of capacitor banks; generators; and other testing material (Taffet et al., 1989; Simmons, 1992). About 99\% of the tritium shipped to Site 300 was used at Buildings 850 (95\%) and 851 (4\%), so the debris placed in these pits contains the majority of tritium residue at Site 300 (Buddemeier, 1985). The Pit 3 Landfill was used from 1958 until 1967 and contains approximately 26,330 cu yd of material contained in a 6, 200 sq yd area (Lindeken and Hieb, 1988). The Pit 4 Landfill 
contains approximately $2,800 \mathrm{cu}$ yd of waste material in $855 \mathrm{sq}$ yd area and was used from 1968 until 1979. The Pit 5 Landfill was used form 1968 until 1979 and contains approximately 29,910 cu yd of waste material in a 9,100 sq yd area. The "panhandle" in the southern part of Pit 5 was originally planned to be a part of the pit, but interviews with Site 300 employees suggest that this section of the pit was never actually excavated (Simmons, 1992). LLNL opened the Pit 7 Landfill in 1978 and ceased depositing waste in it in 1988. The area and volume of Pit 7 are approximately 6,250 sq yd and $31.100 \mathrm{cu}$ yd, respectively. The Pit 4 and 7 Landfills were capped and closed in 1992 in compliance with RCRA requirements. The cap design is intended to prevent corrosion, shallow subsurface interflows, precipitation infiltration, and mobilization of contaminants in Pits 4 and 7. Ground water contamination associated with previous releases from Pit 7 is addressed in the remedial alternatives. Leaching from these unlined landfills resulted in the release of contaminants to be the subsurface. Contaminants in ground water in the vicinity of and downgradient from the pits have been detected in the shallow alluvium (Qal) and underlying bedrock (Tnbs 1$)$. TCE and 1, 1-DCE have been detected in ground water downgradient of the Pit 5 Landfill. VOC concentrations in the vicinity of Pit 5 have shown a declining trend, with TCE decreasing from a historical maximum of 15 uug/L to $3.5 \mathrm{uug} / \mathrm{L}$ in 1998 . Uranium-238 has been identified in ground water downgradient of Pits 3 and 7 . The maximum activities of tritium in ground water near Pits 3 and 5 were detected in 1998 indicating continued releases of tritium form these pits. Although elevated tritium activity was detected $n$ shallow soil between Pit 3 and Pit 4 , tritium has not been detected at elevated levels in ground water form wells directly downgradient of Pit 4. Nitrate (as NO3) and prechlorate have also been detected in ground water downgradient of the Pit 7 Complex. Tritium and uranium-238 have also been identified as COCs in surface soil and subsurface soil/bedrock in the vicinity of the Pit 7 Complex.

\section{THE PROBLEM}

Significant issues have been identified:

1) DOE is continuing to investigate the amount and distribution of tritium and uranium sources in the landfill waste. It is essential to characterize the main contaminant sources in the landfills before modeling can be performed or potential remedies evaluated.

2) The magnitude and extent of uranium contamination in ground water resulting from DOE activities relative to natural sources of uranium is still being determined.

3) The implementability and permanence of permeable reactive barriers, in situ stabilization, freezing, or any other source control technologies other than excavation and/or capping have not been fully evaluated.

DOE has developed a place to address these issues but two important general questions remain unanswered for which we are requesting lead lab support to help answer:

1) Are there any technologies to characterize (i.e., tritium and uranium concentrations in soil moisture) the source areas in the Pits with minimal Pit invasion?

2) Are there any other technologies (besides those listed above) that will control the P7C source areas and which one is the most cost-effective? 


\section{THE STEPS IN LIFE CYCLE ANALYSIS}

1. Defining the Problem - Life cycle analysis of a problem begins by working through and clearly defining the problem that needs solution. This step focuses on (1) ensuring that we are addressing the real problem, not merely a symptom; (2) specifying the scope of the study and the inventory to be addressed; and (3) educating those involved in the decision making process with the issues and the process itself.

2. Specifying Criteria for Evaluating Possible Solutions - The second step involves developing criteria by which to evaluate the decision alternatives. These criteria should be developed by people familiar with the issues surrounding the problem. In this case, the criteria chosen for remedy evaluation included effectiveness, permitting risk, implementability, health and safety risk, cost, public acceptability, long-term liability, and technical maturity.

3. Constructing the Alternative Possible Solutions - For better-known issues, the alternatives may already be well known and defined. In other cases, alternatives considered in other but similar situations may be borrowed for consideration. Brainstorming may be required to generate alternatives. The set of alternatives should include alternatives that are reversible, are multipronged (i.e., entail a portfolio of actions to improve learning potential and to guard against unexpected events), and are a synthesis of actions over time, or a combination of remedial technologies. In situations of great uncertainty, alternatives employing an incremental strategy should be included: small steps, monitoring, reassessment, additional small steps, etc.

4. Evaluating the Alternatives - Analytical methods are then used to evaluate how well each alternative satisfies each evaluation criterion. To begin, a detailed flow diagram is drawn for each alternative. The flow diagram includes every step in the life cycle, regardless of the organization involved or the time at which it occurs. This step aims to document the financial, environmental, health and safety, and other impacts of the alternatives.

Uncertainty analysis is performed to take into consideration the uncertainty in the underlying variables and provide a truer picture for decision makers. Frequency charts describe the range of possible outcomes and the likelihood of occurrence. Sensitivity analysis and value-of-information analysis are used to determine where additional investigation is warranted - i.e., does the potential benefit of additional investigation justify the cost of obtaining the information? An iterative process is used in which decision alternatives are revised as preliminary analysis suggests new, better alternatives.

5. Making the Decision - After participants have gone through the preceding steps, with iterations to develop improved alternatives, the decision often becomes clear. Arriving at reasonable and defensible decisions, however, may be challenging in situations where none of the decision alternatives is dominant, or where not enough information is available to precisely or accurately assess impacts of one or more alternatives. If no alternative is best on every criterion, it may be possible to mount a logical argument in support of one of the alternatives. Or it may be possible to eliminate alternatives that do not meet minimum criteria thresholds. After one or more alternatives have been eliminated, it may be clear which of the remaining alternatives is preferred.

In situations where it is difficult to identify a preferred alternative, the alternatives can be ranked using multi-attribute decision analysis, in which the results of the life cycle analysis are combined with weighting factors to produce an aggregate score for each alternative. The weighting factors reflect judgments regarding the relative value of making improvements according to one criterion (e.g., life cycle cost) relative to making improvements according to another criterion (e.g., programmatic impacts). Ideally, the weighting factors are defined through a consensual process that includes stakeholders.

Analyses are also performed as part of this step to identify conditions under which the rank order of the alternatives would change. Finally, life cycle analysis uses a variety of visualization techniques to synthesize all the information and communicate the results. 
APPENDIX E PHOTOGRAPHS
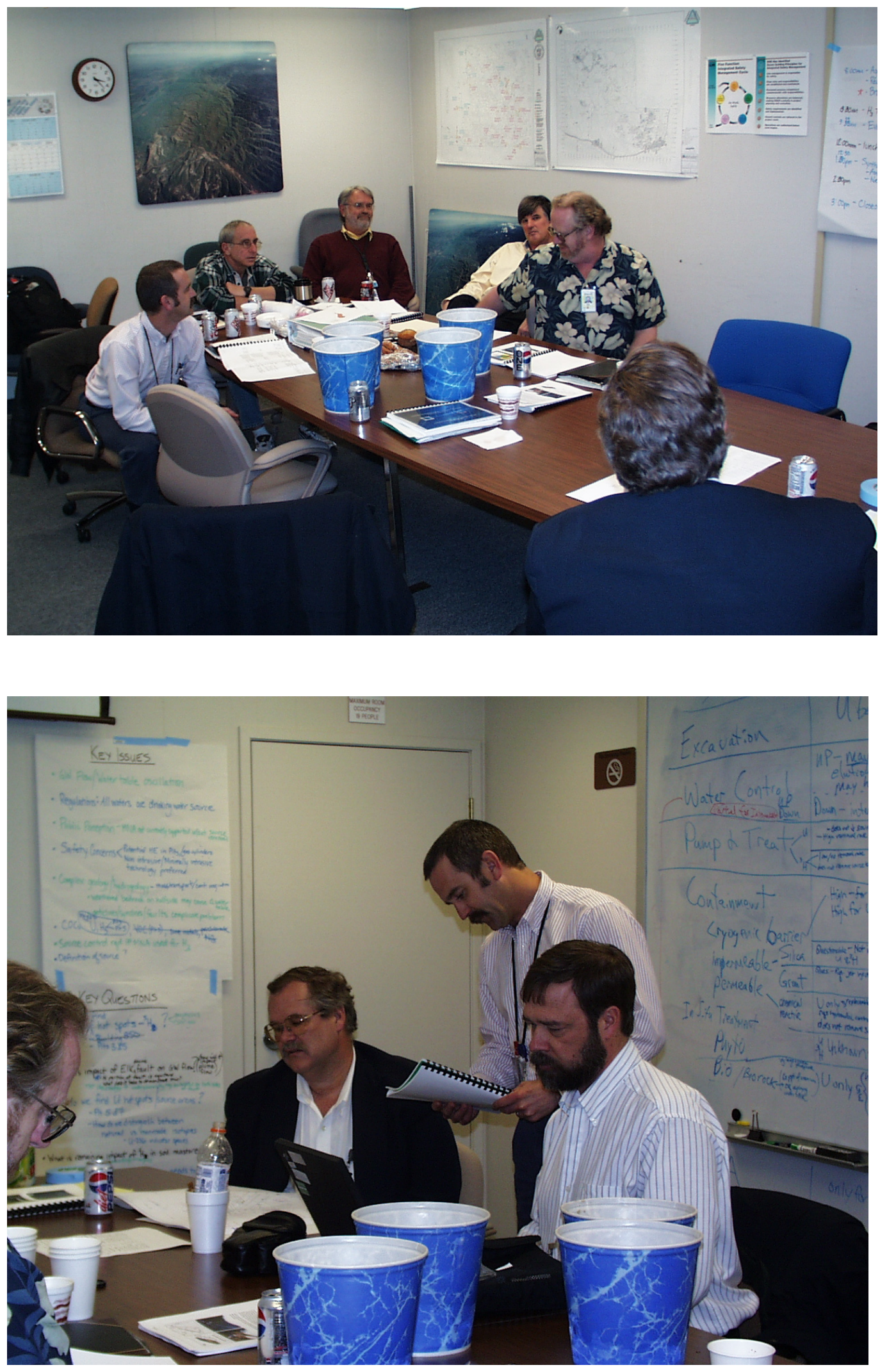

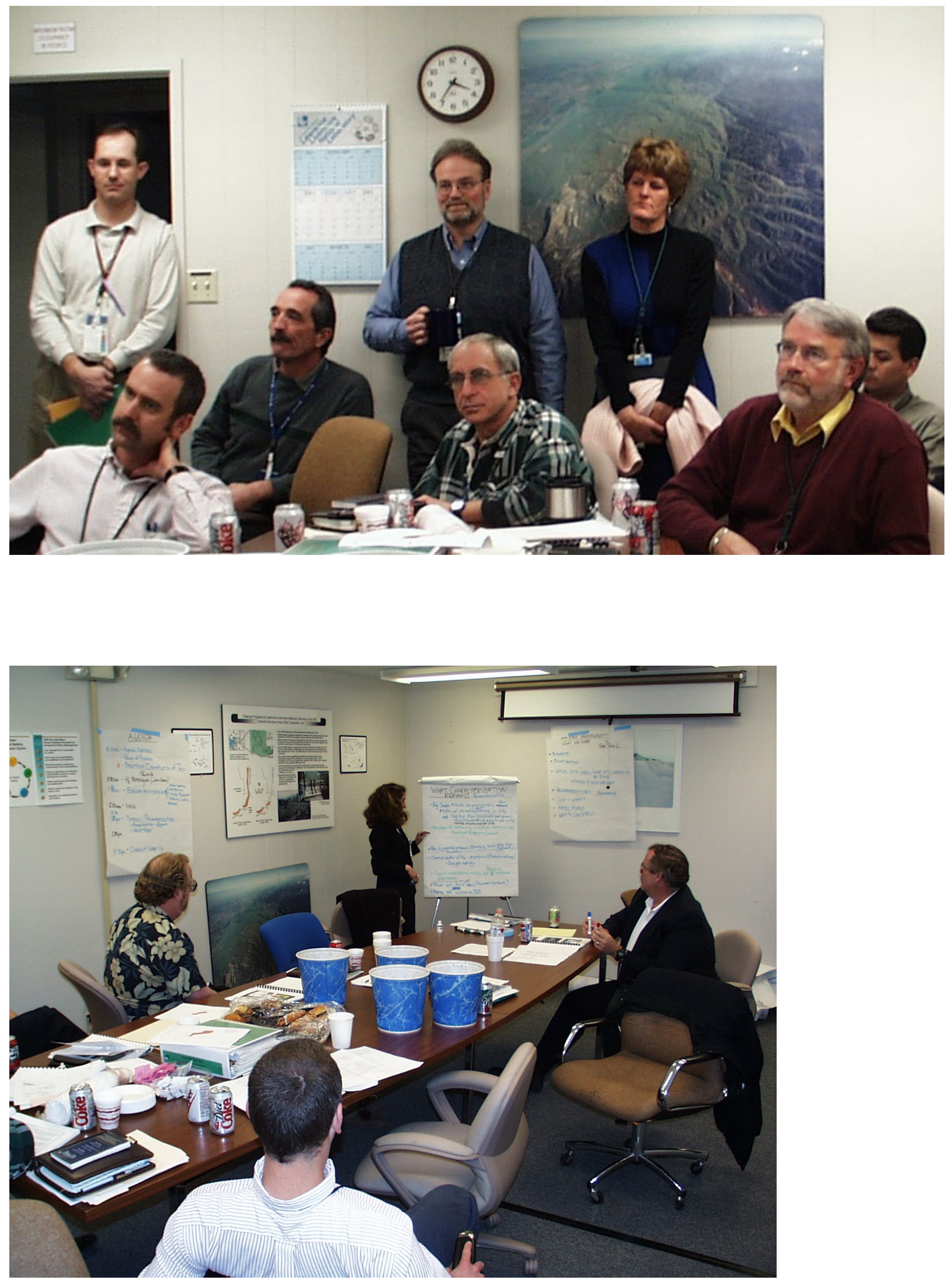